\title{
EDITORS' STATEMENT
}

The idea for this anthology began on camelback. In January 2006, we were in Jordan doing research on the aniconic practices of Nabatean polytheism. At the time, Aaron Tugendhaft had already begun work curating "Idol Anxiety" for the University of Chicago's David and Alfred Smart Museum of Art. The exhibition, which would explore the diversity of practices associated with the notion of idolatry, was to run from April to November 2008. Tugendhaft had the idea of preparing an anthology of essays to complement the show and asked Josh Ellenbogen if he would act as coeditor. Ellenbogen agreed and work began on the present volume. It soon became apparent that the exhibition would come and go long before the anthology would be ready for publication. This allowed us to loosen the bonds between exhibition and book. Though they retain the same title, the two have become more cousins than siblings. Limitation of space restricted the exhibition to objects of a strictly religious character, preventing an exploration of idolatry's relevance beyond the realm of religion. Certain of the essays in this volume were accordingly chosen to broaden the themes of the show. Conversely, not all of the themes and cultures treated in the exhibition have found their way into the book; our beloved Nabateans, for example, had a cameo appearance in Chicago but find no mention here beyond this "Statement." Above all, while the show was an essay in a single voice, in putting together this volume we have embraced the multiplicity of voices natural to the anthology form.

We would like to extend a special thank you to Ike Harijanto for her help in copyediting and indexing this volume.

Josh Ellenbogen

Aaron Tugendhaft 

I DOL A NXIETY 
